ventilation alone may occasionally restore normal rhythm after cardiac arrest, but the full process of rhythm identification and defibrillation, or pacing in the case of asystole, is usually required. When a defibrillator is not available and the heart is in ventricular fibrillation, intravenous procaine amide or lignocaine with continued cardiac massage and ventilation may occasionally restore sinus rhythm and should always be tried. The analeptic drugs frequently found in resuscitation trays are of little or no value.

The patients most likely to experience serious cardiac arrhythmias, periods of hypotension, or myocardial infarction during these diagnostic procedures are those over the age of 50 knəwn to have heart disease, particularly coronary artery disease or hypertension. A basic precaution would be to ensure that all medical and ancillary staff are well tutored in the principles and practice of resuscitation. ${ }^{9}$

Clearly the risks of such disasters are very small, and many clinicians will have carried out the investigations mentioned for many years without encountering such problems. It therefore would be unrealistic to suggest that these investigations should be undertaken only where complete resuscitative facilities are available. An awareness of the possible hazards, careful selection of patients, and a knowledge of resuscitative techniques should provide adequate safeguard against mishap.

\section{Congenital Cardiac Malformation and Facial Weakness}

In 1967 Glen Cayler" reported an "epidemic" of the hitherto undescribed association of ventricular septal defect with a persistent unilateral facial paralysis involving only the mentalis and the quadratus labii inferioris muscles, which are supplied by a single branch of the facial nerves. The paralysis did not cause facial asymmetry and was apparent only when the child cried. The first case was seen in June 1966, and four further cases of the association of this form of paralysis with congenital heart malformation were seen before the end of the year and were all born within a 100 miles of Sacramento. Three had ventricular septal defect, and Cayler now reports 9 further cases ${ }^{2}$ from the same area, making 14 in all, of whom 7 were born in Sacramento itself. Three had a full tetralogy of Fallot, 8 had ventricular septal defect by itself or with other heart lesions, and 1 had mild valvar pulmonary stenosis. Congestive failure developed in 8. The sex distribution was 5 males to 9 females. All cases were sporadic and none of 19 sibs had any malformation. In addition to the main pair of malformations, 3 patients were mentally retarded, and 2 of these were microcephalic ; 4 had skeletal malformations, including 2 with radial aplasia ; 1 had an imperforate anus, 1 anal stenosis, and 2 umbilical herniae ; and 1 had aplasia of the right kidney and a branchial cleft anomaly.

The pregnancies were unremarkable, with no infectious disease; nine of them started in the summer months.

Cayler, G. G., Pediatrics, 1967, 40, 666.

'Cayler, G. G., Archives of Disease in Childhood, 1969, 44, 69.

3 Holt, M., and Oram, S., British Heart fournal, 1960, 22, 236.

' Feingold, M., in Year Book of Pediatrics (1966-1967), 1967, p. 328. ed. S. S. Gellis. Chicago, Year Book Medical Publishers.
Chromosome studies showed no specific changes, but it was considered that there was an excess of breaks present.

This association of malformations is remarkable and worth looking out for. If an infant shows a weakness of the lower lip when crying it suggests that a careful examination should be made of the heart. The cause of the condition remains $\Phi$ obscure. Cayler notes, however, the embryonic proximity of $\frac{\Omega}{c}$ the hyoid arch and the developing heart in the 6-mm. embryo $\Rightarrow$ and also the known association ${ }^{3}{ }^{4}$ of aplasia of the radius with $\stackrel{?}{+}$ atrial and ventricular septal defects.

\section{Donors for Transplants}

No change is to be made in the law governing human trans- $f$ plantation. Sir Hector MacLennan's advisory group, ${ }^{1}$ set $\mathscr{C}_{\mathrm{W}}$ up in January, reported ${ }^{2}$ earlier this week, and $\mathrm{Mr}$. Crossman $\overrightarrow{\mathrm{N}}$ has let it be known that the Government intends to take no action until there is a clearer consensus of medical and public opinion.

In its report the advisory group agreed that the supply of $\overrightarrow{0}$ organs for transplantation ought to be increased-“" a reput- $\frac{c}{<}$ able and, in skilled hands, proven technique of saving life should not be held back by obsolete law or by lack of infor- $\vec{\oplus}$ mation." The group also agreed that the public had a right to safeguards, and it recommended that the death of a potential donor should be certified by " two doctors, one of whom should be at least five years registered, each independent of the transplant team and without regard to the possibility of $\frac{\mathbb{D}}{\mathbb{D}}$ a transplant." The report was adamant that transport of patients between hospitals for the purposes of transplantation must be restricted to moving the recipient.

The advisory group did not agree on recommendations for changes in the law. Six of the eleven members favoured contracting out. They would require an effective mechanism for recording objection and an obligation on transplant teams to search the register. With these provisos surgeons should 3 . be able to remove organs " unless there were definite indica- $\dot{\delta}$ tions that the deceased had objected." The five others advised limited amendment of the present law. The Human 0 Tissue $\mathrm{Act}^{3}$ provides that the person lawfully in possession of a body may authorize removal of parts of it if, having $\rightarrow$ made such reasonable inquiry as may be practicable, he has no reason to believe there was any objection before death by the deceased or after it by any surviving relative. These phrases should be redefined, said the minority report: the hospital authority should be specified as lawfully in possession of the body until it was claimed by the executors or next $\frac{\mathscr{\Phi}}{\mathscr{D}}$ of kin, and the persons with a right to be consulted and the $\stackrel{\oplus}{+}$ scope of the inquiry should also be defined. More publicity should be given to the procedures under the existing law; $\stackrel{0}{\mathbb{D}}$ efforts should be made to identify potential donors or objec-

1 The membership of the advisory group is as follows: Sir Hector $\underset{<}{ }$ MacLennan (chairman), Professor R. Y. Calne, Mr. D. Currie, Rev. Professor S. R. Dunstan, Mr. J. Garfield, Professor W. S. Peart, O Dame Muriel Powell, Dr. G. L. B. Thurston, Miss Katharine Whitehorn, Sir Michael Woodruff, and Baroness Wootton of
Abinger.

- Advice from the Advisory Group on Transplantation Problems on the Question of Amending the Human Tissue Act 1961. London, H.M.S.O. 1969 . 1s. 3d.

3 Human Tissue Act, 1961.

4 Calne, R. Y., British Medical fournal, 1969, 2, 566. 
tors in some unique, recognizable, and durable way; and young people at school, college, or university should be approached to obtain their consent to the use of their organs after death.

Good results from transplantation depend on good tissue matching, and this can be achieved only if there is an adequate supply of donor organs and some registry for potential recipients and donors. Many family doctors would like to be able to tell their patients whom to contact if they wish to donate their organs after their death. This may be a task that could be tackled by one or more voluntary organizations, but it is likely to be expensive, and experience in Europe ${ }^{4}$ suggests that a computer is essential if the system is to be efficient. Can a voluntary organization provide a complex service of this kind ? It would seem to be a task more suitably undertaken by the Department of Health and Social Security. But on the question of individual consent the Government is right to postpone changes in the law until public opinion is clearly in their favour.

\section{Arteriography in Splenic and Hepatic Disease}

Selective arteriography of the coeliac axis and its branches is an important technique for investigating diseases of the liver, spleen, and pancreas. The aorta is approached percutaneously from the femoral artery, and contrast medium is injected through the catheter into the orifices of the emergent arteries. ${ }^{1-3}$

The technique is valuable in detecting tumours, because these disturb the normal vascular anatomy of the organ. In liver cancer the normal vessels are displaced and distorted, while abnormal vessels are seen entering the area of the tumour. Another noteworthy feature is the diffuse staining of the tumour due to an accumulation of contrast medium in its capacious, thin-walled, vascular spaces. ${ }^{4}$ Cysts and tumours of the spleen are also well delineated, and an indication of the degree of malignancy of the condition is often provided. ${ }^{5}$ Selective arteriography is useful in the early diagnosis of pancreatic cancer, ${ }^{6}$ in which displacement, stenosis, and obliteration of normal vascular channels are more usually seen than are tumour vessels or tumour staining. This may be due to the necrotic, cystic nature of many pancreatic cancers. $^{7}$ The method has also been used with advantage in delineating the portal vein in those cases of portal hypertension in which the standard splenoportography performed percutaneously through the splenic parenchyma proves unsatisfactory, or when the spleen has already been removed. $^{3} 8$

L. Blendis, L. Kreel, and $R$. Williams have recently analysed a series of 161 selective coeliac angiograms in an attempt to correlate the comparative sizes of the coeliac axis

Ïdman, P., Acta Radiologica, 1956, 45, 1.

- Ödman, P., Acta Radiologica, 1958, Suppl. 159.

- Stulberg, H. J., and Bierman, H. R., Radiology, 1965, 85, 46.

- Rösch, J., Clinical Radiology, 1966, 17, 183.

Lunderquist, A., Acta Radiologica, 1965, Suppl. 235

Sammons, B. R., Neal, M. P., Armstrong, R. H., and Hager, H. G., American fournal of Roentgenology, Radium Therapy, and Nuclear Medicine, 1967, 101, 345.

- Boijsen, E., Ekman, C.-A., and Olin, T., Acta Chirurgica Scandinavica, $1963,126,315$

- Blendis, L., Kreel, L., and Williams, R., Gut, 1969, 10, 85. and the splenic and hepatic arteries with the size of the spleen (measured by angiography) in conditions in which there was splenomegaly and in liver disease. ${ }^{9}$ They also investigated the relationship between splenic blood flow and vascular size. $\underline{T}$ Of their cases half were controls suffering from other abdomi- $\bar{z}$ nal conditions necessitating angiography, and about a third $\stackrel{\otimes}{\varrho}$ of these had systemic hypertension. The remainder consisted $c$ mainly of hepatic cirrhosis (some with portacaval shunts), $\underset{\vec{s}}{\vec{\rho}}$ hepatic tumours, and tropical splenomegaly.

Both the coeliac axis and the splenic artery were dilated in patients with cirrhosis and in those with portacaval $\overline{\bar{D}}$ anastomoses. There was also dilatation of these arteries in $\bar{\phi}$ tropical splenomegaly, and in most cases of portal-vein thrombusis and liver tumour. By contrast the hepatic artery was not dilated in cirrhosis, tropical splenomegaly, or portal- $\overrightarrow{-}$ vein thrombosis, but there was significant widening in cases $\vec{\omega}$ of portacaval anastomosis and liver tumour. There was $\stackrel{\rho}{\circ}$ lengthening of the splenic artery in patients with cirrhosis 3 and in those with a portacaval anastomosis, but not in cases $\dot{\omega}$ of tropical splenomegaly.

The spleen was enlarged in cases of cirrhosis but was within the normal range in the great majority of patients with a $\vec{N}$ portacaval shunt. There was a close correlation between the width of the splenic artery and the size of the spleen in cirrhotic and control patients, but no such relation existed between spleen size and the length of the splenic artery, or $\vec{c}$ the widths of the hepatic artery and the coeliac axis. There was moderate splenomegaly in patients with liver tumours irrespective of the presence of cirrhosis. The total blood flow in the spleen was related to the degree of enlargement of the organ. It also correlated with the width of the splenic artery in cases of cirrhosis and blood dyscrasias but not in tropical splenomegaly.

This investigation throws light on the gross vascular $\frac{0}{\infty}$ changes occurring in diseases of the liver and spleen. Of particular interest is the effect of portacaval anastomosis in widening the hepatic artery in cirrhotic patients. The hepatic arterial dilatation associated with liver tumours can be explained as due to an increased demand for arterial blood, but the enlargement of the spleen and the dilatation of the splenic artery require further investigation. The failure of portacaval anastomosis to narrow the dilated splenic artery 3 . in cirrhosis is also surprising in view of the reduction in $\dot{\delta}$ size of the spleen that follows this operation. More work will be necessary to confirm these findings and assess their $\frac{0}{2}$ significance.

\section{Pyrexia of Unknown Origin}

One of the commonest clinical problems a patient may $\stackrel{\mathscr{D}}{\rightarrow}$ present is a continuing pyrexia in the absence of localizing symptoms and signs. A systematic approach to its elucidation includes a careful history, frequent physical examination, $\stackrel{\mathbb{Q}}{\stackrel{Q}{Q}}$ four-hourly records of temperature and pulse, and certain $\stackrel{\mathbb{Q}}{\mathscr{Q}}$ investigations. When a specific system is found to be affected, efforts are directed to its investigation and the patient is noo longer regarded as an ambiguous case of P.U.O.

The concept of P.U.O. has changed with the advent of chemotherapy. Inadequate treatment may mask certain

1 Effersøe, P., Danish Medical Bulletin, 1968, 15, 231.
2 Effersøe, P., Danish Medical Bulletin, 1968, 15, 240. 